\title{
Demographic consequences of harvesting: a case study from a small and isolated moose population
}

\author{
Ivar Herfindal ${ }^{1, *}$, Aline Magdalena Lee ${ }^{1}$, Sandra Hamel ${ }^{2,3}$, Erling Johan Solberg ${ }^{4}$, \\ Bernt-Erik Sæther ${ }^{1}$ \\ ${ }^{1}$ Centre for Biodiversity Dynamics, Department of Biology, Norwegian University of Science and Technology, \\ 7491 Trondheim, Norway \\ ${ }^{2}$ Department of Arctic and Marine Biology, UiT the Arctic University of Norway, 9019 Tromsø, Norway \\ ${ }^{3}$ Département de biologie, Université Laval, Québec G1V 0A6, Canada \\ ${ }^{4}$ Norwegian Institute for Nature Research (NINA), 7485 Trondheim, Norway
}

\begin{abstract}
Harvesting can have a substantial impact on population dynamics and individual performance in wild populations. While the direct consequences of harvest on individual survival and population growth rate are often apparent, harvesting can also have indirect and more subtle demographic consequences. Disentangling these consequences, however, requires in-depth knowledge of individual life histories of both females and males in the population. Here, we summarise demographic research on a population where such data exist: the Vega moose population in northern Norway. In this population, vital rates vary considerably among both females and males, and harvesting increases this variation by generating positive covariation between reproductive performance and survival. The skewed age and sex structure, which is typical of many harvested populations, also has demographic consequences: it reduces the ratio of effective to total population size and influences variation in vital rates in males and females. The moose harvest at Vega is structured by age- and sex-specific quotas, but it is not intentionally selective regarding size or other phenotypic characteristics. Still, harvest selection for earlier birth rates and larger calves was apparent, likely due to habitat-performance relationships and habitat-specific harvest mortality. Together, the bulk of research on this population shows that harvesting impacts population demography through many different pathways, with some being more subtle than others. These complex pathways influence the demographic variance and affect stochastic processes such as population growth, genetic drift, and rates of evolutionary change, and they must therefore be acknowledged in management plans to achieve sustainable harvesting.
\end{abstract}

KEY WORDS: Hunting $\cdot$ Harvest selection $\cdot$ Individual heterogeneity $\cdot$ Vital rates $\cdot$ Sustainable harvest $\cdot$ Inbreeding $\cdot$ Alces alces $\cdot$ Demographic rates

\section{INTRODUCTION}

Sustainable management of natural resources requires an understanding of how climate change and harvesting affect populations and ecosystems. To reach such an understanding, however, we first need

${ }^{*}$ Corresponding author: ivar.herfindal@ntnu.no knowledge about the fundamental consequences of harvesting on population processes, irrespective of environmental change. Although there is a consensus that harvest should be targeted towards sustainability (e.g. UN General Assembly 2015), strong economic pressures for maximising short-term harvest

(C) The authors 2021. Open Access under Creative Commons by Attribution Licence. Use, distribution and reproduction are unrestricted. Authors and original publication must be credited. 
yield may compromise this goal (Sæther et al. 2001). In contrast to fisheries, where individual variation in harvest mortality is mainly related to body size, harvesting of many wildlife species such as most ungulates is allowed to be targeted towards specific age, sex, or even reproductive classes. Harvesting quotas are therefore often quite specific in many of these species (Apollonio et al. 2010). For instance, if the aim is to maximise population productivity and number of individuals that can be shot, quotas are often aimed at males and juveniles/subadults that have not yet started to reproduce (Beddington 1974, Caughley 1977, Sæther et al. 2001, Lavsund et al. 2003). This generates large variation in harvest mortality among individuals according to their age, sex, or reproductive status. Harvesting can also have other, more subtle consequences, such as generating artificial selection on phenotypes and thereby influencing the magnitude of genetic drift (Ericsson et al. 2001, Sæther et al. 2009, Sæther \& Engen 2019) and the capacity to adapt to environmental fluctuations, or behavioural responses that affect individual fitness (Edeline et al. 2007, Coltman 2008). In turn, these consequences of harvest may affect long-term sustainable yield during periods with large environmental changes, such as an altered climate (Morrongiello et al. 2019). Although harder to detect, their impact on dynamics and evolutionary processes should not be ignored when developing management strategies to ensure the long-term sustainability of harvest (Coltman 2008).

Recent research has clearly demonstrated the strong influences that individual variation in vital rates can have on population dynamics, demography, and evolutionary processes (Engen et al. 2003, Hamel et al. 2018). This variation can be caused by differences in the underlying probability of survival and reproduction among individuals or groups (Cam et al. 2016) or simply by the stochastic realizations of survival and reproduction based on these probabilities (Engen et al. 1998, 2003). When individual differences are persistent through time, they are often termed individual heterogeneity (although the exact definition of this term varies; see Cam et al. 2016). Individual heterogeneity can be fixed (permanent differences in probability of survival or reproduction fixed at, or soon after, birth) or dynamic (persistent differences among individuals caused by realisation of stochastic processes, while the underlying probabilities are the same) (Cam et al. 2016). These different types of heterogeneity are difficult to separate in practice. Here, we use the term individual heterogeneity to mean persistent individual differences, whether they are fixed or dynamic.
Stochastic theory of population growth differentiates between environmental stochasticity, which tends to influence the survival and/or reproduction of all individuals simultaneously, and demographic stochasticity, which is random variation in realised survival and reproduction among individuals (Engen et al. 1998). Demographic variance, $\sigma_{d r}^{2}$ is a commonly used metric of demographic stochasticity. Demographic stochasticity has a negative impact on the growth rate of small populations (Lande et al. 2003), increasing their risk of extinction (Engen et al. 2005b). In addition, demographic stochasticity may reduce the effective population size $\left(N_{e}\right)$ (Engen et al. 2005a), increasing the loss of alleles and genetic drift. These properties make demographic stochasticity a fundamental concept in population ecology and evolutionary biology. Its influence on extinction rate, allele frequency variation, and phenotypic evolution makes it a crucial parameter for understanding the short- and long-term persistence of populations (Engen et al. 1998, 2003, Sæther \& Engen 2019), particularly when they are small and isolated (Lande 1998).

There are several challenges involved in estimating the demographic variance of harvested populations and studying its causes and consequences. First, we need information about survival and reproduction at the individual level for a large proportion of the population, which, for many species, requires a great deal of time and resources to obtain. Second, estimation of age- or stage-specific vital rates often involves sophisticated statistical analyses, for instance, to separate harvest mortality from other sources of mortality. Moreover, to disentangle the different drivers of individual variation in demographic contributions, we need knowledge about other factors such as population density and structure and environmental conditions. Only with such information available can we start to fully understand the causes and consequences of individual variation in vital rates (Hamel et al. 2018, FestaBianchet et al. 2019). Still, it is a challenge to estimate demographic variance in fluctuating age-structured populations, because age dependences in life histories generate time lags in population dynamics (Engen et al. 2009). Using the concept of individual reproductive values can help resolve this issue, because it describes the expected contribution that an individual of a certain age and sex will make towards population growth or evolutionary processes relative to other individuals (Grafen 2006). Accordingly, by using individual reproductive values, it is also possible to estimate total and sex-specific demographic variance for age-structured populations with 
overlapping generations (Engen et al. 2007a,b, Sæther et al. 2007), as is common for harvested species.

Here, we synthesise results from almost $30 \mathrm{yr}$ of research focussing on how harvesting can influence the demographic processes of a moose population on the island of Vega, off the coast of northern Norway (see Fig. 1). Because of the small impact of environmental variation on individual performance and population dynamics (Sæther et al. 2007, Solberg et al. 2007), the Vega moose population is well suited for generating knowledge on the fundamental consequences of harvesting on population processes. In addition, it represents one of few harvested systems where detailed individual data make it possible to investigate the complexity of demographic effects of harvesting.

\section{THE VEGA MOOSE STUDY SYSTEM}

\subsection{The island of Vega}

Vega $\left(65^{\circ} 40^{\prime} \mathrm{N}, 11^{\circ} 55^{\prime} \mathrm{E}\right)$ is an island with an area of $119 \mathrm{~km}^{2}$, located off the coast of Helgeland in northern Norway (Fig. 1), approximately $100 \mathrm{~km}$ south of the Arctic Circle. The island is covered by a mixture of agricultural areas, marshes, and heather Calluna vulgaris-dominated moorland, interspersed with stands of deciduous forests and short-grown pine Pinus sylvestris forests (Angeloff et al. 2004). The deciduous forests are mainly found along rivers and creeks. The southwestern part of the island is more mountainous, with Trollvasstinden $(800 \mathrm{~m}$ above sea level) as the highest point. The mountain area is steep and not utilised by moose, leaving approximately $80 \mathrm{~km}^{2}$ of the island as moose habitat. The climate is oceanic, with relatively mild winters (November-April temperature: mean $=1.9^{\circ} \mathrm{C}$, range $0.6-3.1^{\circ} \mathrm{C}$ ) and shallow snow cover (November-April snow depth: mean $=4.9 \mathrm{~cm}$, range $0-23.7 \mathrm{~cm}$ ) given the high latitude. The summers are cool and wet (June-August: temperature, mean $=12.5^{\circ} \mathrm{C}$, range $10.8-15.4^{\circ} \mathrm{C}$, precipitation, mean $=73.2 \mathrm{~mm}$, range $33.0-104.4 \mathrm{~mm})$.

\subsection{The Vega moose population}

The moose population on Vega was founded by 1 male and 2 females that swam to the island, about $13 \mathrm{~km}$ off the mainland, in 1985. The population increased by reproduction and subsequent immigrations, and restricted hunting started in 1989. In 1991, hunters killed 2 moose, and 24 individuals were recorded during a helicopter survey in the following winter. Since then, annual harvesting has kept the breeding population between 27 and 40 individuals (see Fig. 2). The population density is well below carrying capacity and it scores high on all performance parameters (Solberg et al. 2011). Calves weigh on average about $160 \mathrm{~kg}$ in autumn $(80 \mathrm{~kg}$ carcass mass, which is body mass minus head, skin, metapodials, bleedable blood and viscera; Sæther et al. 1996), males weigh about $500 \mathrm{~kg}$ at prime age (5-10 yr old), and about $60 \%$ of reproducing females give birth to twins (Markussen et al. 2018). Moreover, as there are no large carnivores on the island, natural mortality rates are low and mainly due to traffic accidents. In the period 1991-2005, the number of moose harvested constituted about $91 \%$ of all calves recruited to the pre-harvest population in the same period of time, indicating that most moose are eventually killed during the hunting season (Solberg et al. 2010). The high fecundity and natural survival combined with a mostly female-dominated sex ratio (Herfindal et al. 2014a) allowed for an annual harvest of 24 moose on average in the period 1991-2018 (Solberg et al. 2010, Statistics Norway: www.ssb.no). Hunting permits are usually issued for a fixed number of calves, adult males, and adult females, but adults can also be split into young (mainly yearlings) and old adults ( $\geq 2.5 \mathrm{yr}$ old) by the hunting right holders. Hunting can occur from 25 September to 23 December, but in most years the start of the hunting season was postponed to the first weekend of October and finished before the end of the same month. The peak rut occurs at the end of September on Vega, indicating that most females have conceived before the start of the hunting season.

\subsection{Studies on the Vega moose population}

The study of the moose population at Vega was initiated in 1992 (see Fig. 2), when 20 of 24 moose present on the island were captured, weighed, and marked with VHF radio-collars (Sæther et al. 2003). In the following years, new calves and immigrants to the island were radio-collared each year, with GPS collars gradually replacing VHF collars after 2004 (Herfindal et al. 2009, Solberg et al. 2011). Almost all captures were conducted with the use of helicopters in January-March, during periods with snow on the ground. The frequent captures ensured that a large proportion $(>90 \%)$ of the breeding population were wearing radio collars during the study period. 


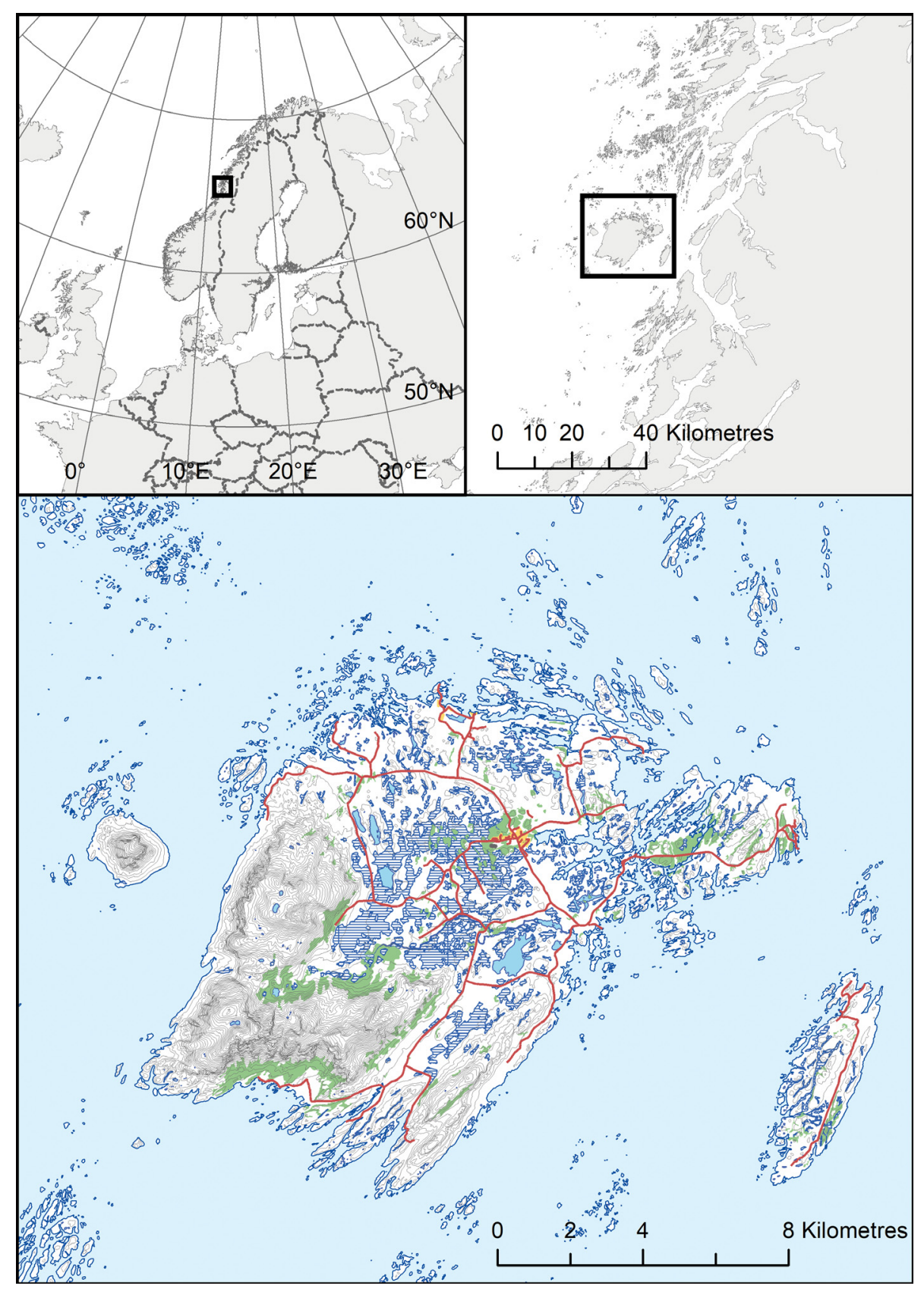

Fig. 1. The island of Vega, Norway, where research on the demographic consequences of harvesting on a moose population has been carried out since 1992. In the lower map, green areas: forests; blue-lined areas: bogs/wetlands; filled blue areas: open water; white areas: open areas (heather, bare mountain); red lines: public roads

The study at Vega was initiated mainly to examine the effect of skewed adult sex ratios on fecundity and calving dates (Sæther et al. 2003, 2004). To achieve this goal, the sex and age structures were manipulated by selective harvesting during the period 1994-1999. In 1994, all adult ( $\geq 1.5 \mathrm{yr}$ ) males in the population were killed after the rutting season (Fig. 2$)$, leaving only young $(\leq 2.5 \mathrm{yr})$ males as poten- tial breeders in 1995 and 1996. The sex ratio was kept quite even (ca. $40 \%$ males) by shooting some cows. Thereafter, the adult sex ratio in the population was reduced to about $25 \%$ males from 1997-1999, while keeping some older males in the population (Sæther et al. 2003, 2004). The population grew rapidly the first $8 \mathrm{yr}$ after colonisation (Sæther et al. 2007) and also experienced similar growth at 


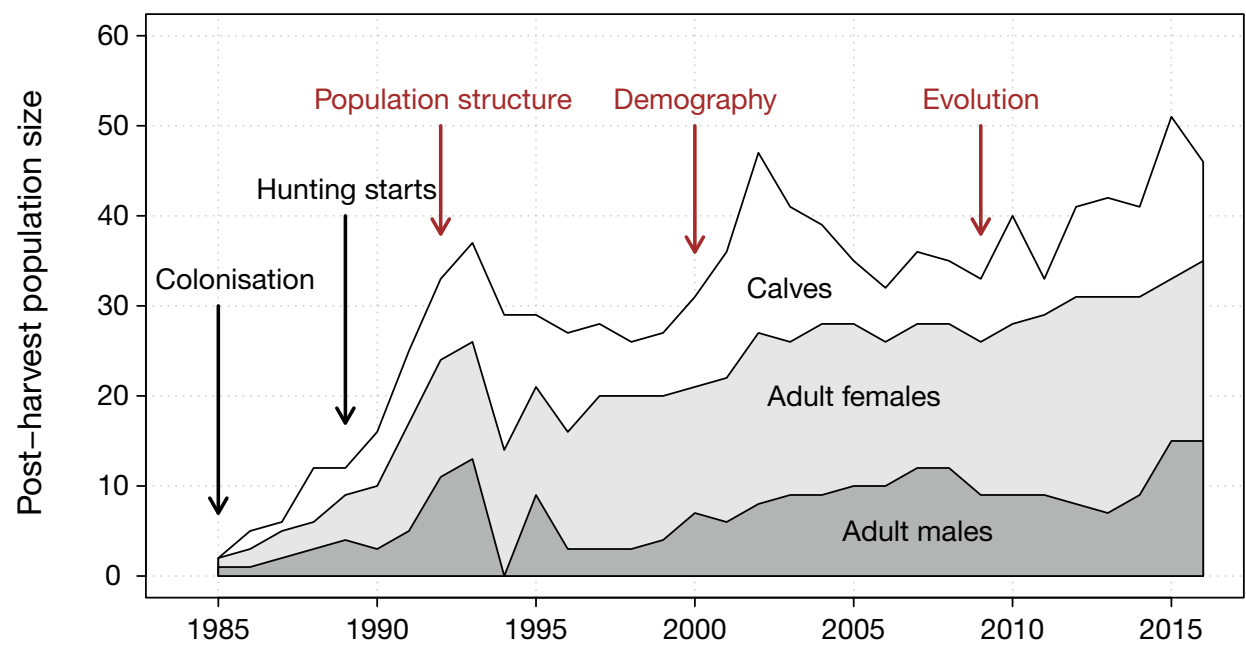

Fig. 2. Dynamics of the post-harvest moose population at Vega, with important events highlighted with arrows. Red arrows indicate when research projects started and the thematic focus of the research

the end of the 'population structure' research period (Fig. 2) before being stabilized through regular harvest (Fig. 2). Later studies at Vega have focussed on establishing a pedigree to investigate the evolutionary consequences of harvesting (Kvalnes et al. 2016).

\section{WHAT HAS THE VEGA MOOSE POPULATION TAUGHT US ABOUT HARVESTING IMPACT ON DEMOGRAPHY?}

\subsection{Demographic effects of population properties}

The age- and sex-specific harvesting that ungulate populations experience strongly affects their social structure (i.e. age and sex distribution). Structured harvesting quotas are often used to increase yield in terms of biomass or numbers of harvested individuals. This strategy is based on deterministic harvesting models showing that the annual yield can be enhanced by increasing the share of adult males and juveniles of both sexes in the harvest (Beddington 1974). However, stochastic processes affecting the population may alter the optimal harvesting strategy to be more conservative due to a higher variation in the annual yield (Sæther et al. 2001). Such strategies could be achieved by introducing harvest thresholds to relax harvest pressure at critically low population sizes (Lande et al. 1995, 1997). This demonstrates the importance of acknowledging stochasticity in demographic rates and in the environment for achieving sustainable harvest of populations (Lande et al. 1995, 1997, Engen et al. 1997, Sæther et al. 2001). Moreover, as variation in age- and sex-structure strongly affects the effective size of a population (Engen et al. 2005a), the longterm ability of such sex- and age-selective harvesting strategies to maximise the annual yield can be questioned (Ericsson et al. 2001). In the Vega moose population, increasing the share of adult bulls in the harvest, and thus decreasing the share of calves, led to a decrease in $N_{e}$ (Sæether et al. 2009) because these structural changes affected the demographic variance. This illustrates how a harvest strategy aimed at particular age groups and sexes can alter the genetic composition of a population by affecting the number of breeding males (Sæther et al. 2009, Sæther \& Engen 2019) and indicates that harvest strategies for optimising short-term yield may have unfavourable long-term genetic consequences.

For polygynous species, most harvesting models assume that only a few males are needed to fertilise all fecund females (e.g. Mysterud et al. 2002). However, the consequences of a skewed sex ratio or changes in the age structure on individual performance have rarely been examined in natural populations. At Vega, we investigated the demographic consequences of sex-skewed harvesting by manipulating the population's sex and age structure into an overdominance of adult females and young males, respectively. Such a population structure occurs in several heavily managed moose populations in Fennoscandia (Lavsund et al. 2003, Solberg et al. 2006). The results showed that the number of calves produced remained mostly unchanged even when only a few or mainly young males were present in the population (Sæther et al. 2003, Markussen et al. 2018) but that calves were born substantially later 
than in years with more balanced sex- and agestructure (Sæther et al. 2003). As late-born calves are smaller on average as adults (Solberg et al. 2007, 2008) and size seems to be a fundamental determinant of reproductive success in moose (Sæether \& Heim 1993, Sæther et al. 1996), a sex-biased population structure can have unintended long-term consequences for the population growth rate. In addition, the male age structure seems to affect the secondary sex ratio, as significantly more male than female calves were sired by older than younger fathers (Sæther et al. 2003), a pattern that is supported when examining moose populations across Norway (Bjørneraas et al. 2009). Hence, although population structure had only minor immediate effects on the females' probability of reproduction, smaller calves and changes in sex ratios at birth generated longlasting cohort effects on offspring characteristics that can affect population growth (Solberg et al. 2007, Markussen et al. 2018).

\subsection{Individual heterogeneity in the Vega moose population}

Despite the favourable environmental conditions for moose on Vega (Sæther et al. 2007, Solberg et al. 2011), there is substantial individual variation in female reproductive performance in terms of age at first reproduction, annual probability of reproduction, and lifetime twinning rate. Longevity is a fundamental component of lifetime reproductive success in long-lived species (Clutton-Brock 1988, Ericsson et al. 2001, Neumann et al. 2020), and on Vega, longevity is almost entirely determined by harvesting, with the exception of some natural mortality in the first year of life (Kvalnes et al. 2016, Stubsjøen et al. 2000). Moose cows can start mating in their second autumn and give birth the following spring, but age at first reproduction depends on female body mass (Sæther et al. 1996). Accordingly, larger female calves at Vega have a higher probability of giving birth at age 2 than smaller calves (Markussen et al. 2018), and females that reproduced at $2 \mathrm{yr}$ of age are more likely to reproduce and to produce twins in subsequent years than are females that delay their start of reproduction (Markussen et al. 2018). This contradicts the usual trade-offs expected between earlyand late-life investment in reproduction (Stearns 1992). Indeed, it has been demonstrated that individual variation in resource acquisition and allocation can mask the trade-offs expected by life-history theory (Stearns 1992), leading to positive rather than negative correlations among life-history traits at the individual level (van Noordwijk \& de Jong 1986). The positive correlation between current and future reproductive success on Vega is probably caused by persistent individual differences in female quality, which in turn may be caused by maternal habitat use and early body growth (Markussen et al. 2018, Ofstad et al. 2020). Initially, we expected low variation in habitat use on an island the size of Vega, where moose can easily gain information about the distribution of resources. However, we actually found the variation in habitat use to be considerable, and that the mothers' habitat use also affected the body mass of their calves (Ofstad et al. 2020). This suggests that individual variation in behaviour and movement patterns can provide important contributions to the distribution of fitness-related life-history traits within a population (McLoughlin et al. 2007, Allen et al. 2017, Rolandsen et al. 2017).

Because harvesting is the main cause of mortality of adult females at Vega (Kvalnes et al. 2016, Stubsjøen et al. 2000), we did not expect to observe survival costs of reproduction. Compared to reproductive costs, survival costs of reproduction are more unlikely and have been less frequently reported in such long-lived species (Hamel et al. 2010) because survival is strongly canalized (Gaillard et al. 2000, Gaillard \& Yoccoz 2003). Still, the probability of being shot is not random among females at Vega. Harvest mortality is lower among productive females because hunters, for ethical reasons, are unlikely to shoot a female accompanied by a calf (Markussen et al. 2018), and consequently, the frequency of orphaning is estimated to be low in Norway $(1.7-1.9 \%$ of moose calves; Veiberg et al. 2016). For this reason, the most productive females are also winners with respect to survival, as a female with twins must lose both her calves before she becomes a real target (Markussen et al. 2018). This suggests that selective hunting based on reproductive status can impose strong artificial selection pressure in harvested populations.

Assessing the reproductive performance of males is challenging in species without paternal care. Individual heterogeneity in males' vital rates and life-history traits have therefore mainly been investigated for mortality, at least in mammals (Hamel et al. 2010, Bleu et al. 2016). However, molecular genetic tools have now made it more feasible to assess the reproductive success of males. At Vega, we have a near complete pedigree for all individuals present between 1985 and 2016 (Haanes et al. 2013), providing an ideal opportunity to assess heterogeneity in both 
reproduction and survival among males. As expected for polygynous species, reproductive performance among males in a given year is highly variable, measured both as the number of successful matings and number of calves sired (Ofstad 2019). This difference persists over entire lifespans (Markussen et al. 2019), resulting in a considerably higher individual variation in lifetime reproductive success among males than females (Markussen et al. 2018, 2019). Interestingly, a positive temporal covariation in reproductive performance also exists in males, as most males that started reproducing at a young age had higher annual mating success during their life than males that delayed first reproduction (Markussen et al. 2019). Juvenile body mass was an important determinant of reproductive performance, emphasising the limited possibilities for males to compensate for a bad start in life (Solberg et al. 2008). The presence of such a positive covariation could also depend on the mating system. In sequentially polygynous species such as the European moose, where males do not frequently engage in energetically demanding fights, the cost of reproduction may be lower than in harem-holding species where males spend a large amount of energy in fights to obtain and protect a harem (CluttonBrock et al. 1982).

When the management goal is to maximise production, harvesting is often targeted at males (Beddington 1974, Sæther et al. 2001, 2004). Thus, at Vega the harvest mortality of males is considerably higher than that of females (Kvalnes et al. 2016, Markussen et al. 2019) but lower among older ( $>2.5 \mathrm{yr}$ ) than younger males. The latter may appear odd in light of the often observed high focus on trophy animals among hunters, but can be explained by the wish of the local management to keep some prime-aged males in the population (Sæther et al. 2004). To avoid excessive hunting of trophy bulls, permits are often split between young (mainly yearlings) and older males based on body size and antler size, which can also explain why the harvest mortality was lower for the most successful males (Markussen et al. 2019). In fact, even among older males ( $>3.5$ yr old), the harvest mortality was more than 4 times higher for unsuccessful than successful males, which we believe is caused by unsuccessful males being smaller and thus more likely to be judged as younger by the hunters (Markussen et al. 2019). Accordingly, selective hunting is adding to the positive covariation among life-history traits in males, and individual differences in early growth is the main determinant of the persistent individual heterogeneity in life-history traits of both male and female moose at Vega.

\subsection{Consequences of individual heterogeneity for demography}

Theoretical models have demonstrated that individual heterogeneity may influence both population dynamics (Vindenes et al. 2008) and evolutionary processes such as genetic drift (Engen et al. 2007b, Lee et al. 2011). In polygynous species, fluctuations in population size are generally driven by variation in the reproductive success and survival of females. However, the persistent differences in reproductive performance seen among female moose on Vega had only a very small effect on the demographic variance in this population (Lee et al. 2017). The effect was somewhat larger when the observed covariation between reproduction and survival was also included, because this covariation amplifies the individual differences. Females that had twins were not only more likely to produce twins again in the future if they survived, they were also more likely to survive, causing a synergistic effect between these 2 mechanisms. Nonetheless, the combined effect on the expected time to extinction was negligible (Lee et al. 2017). Thus, female individual heterogeneity seems to have minor effects on population dynamics in this population. This is likely in part because most female moose do eventually start producing twins, causing the differences between individuals to decrease over their lifetimes (Markussen et al. 2018). In fact, theoretical analyses indicate that individual differences in reproduction would have to be quite extreme to have a substantial effect on the expected time to extinction (Lee et al. 2017).

While mammalian population dynamics are assumed to be driven mainly by females, the genetic composition can be highly influenced by males, due to the high variance in male reproductive success in polygynous species (Clutton-Brock 1988, Markussen et al. 2019, Ofstad 2019). This also holds true for the moose population at Vega. The ratio of $N_{e}$ to total population size $\left(N_{e}: N\right)$ was especially sensitive to the demographic variance of older males in this population (Lee et al. 2020). Persistent differences in reproductive output and covariation between reproduction and survival in females had little impact on this ratio. In males, however, the resulting individual heterogeneity had a greater effect, increasing the demographic variance by almost $13 \%$. Overall, persistent individual differences decreased $N_{e}: N$ from 0.34 to 0.28 , which represents a change in the asymptotic $N_{e}$ from 17 to 14 , using the harmonic mean of the population size between 1992 and $2011(N=50)$ as $N$ (Lee et al. 2020). This represents a substantial change in 
such a small population, showing that individual heterogeneity does in fact play an important role in genetic processes in this population.

\subsection{Harvest selection on phenotypes and life histories}

The extent to which harvest acts as a selective force that results in evolutionary change of phenotypes in wildlife populations has recently been the subject of scientific debate (e.g. Coulson et al. 2018, Festa-Bianchet \& Mysterud 2018). In the moose population at Vega, we can explore the effects of harvesting on phenotypic evolution because individual contributions to population growth are related to differences in a heritable trait - body mass - in both sexes (Markussen et al. 2018, 2019). Such sizedependent demography operating through earlier onset of reproduction in large individuals is a general pattern in Scandinavian moose populations (Sæther \& Haagenrud 1983, 1985, Sæther \& Heim 1993, Sand 1996, Ericsson et al. 2001) and seems to be related to the quality or quantity of available food in late spring or early summer (Sæether 1985, Bø \& Hjeljord 1991, Sand 1996, Herfindal et al. 2006a,b, 2014b). This implies that the timing of birth relative to plant phenology can have important consequences for lifetime reproductive success in moose (Sæther et al. 2003, Markussen et al. 2018, Neumann et al. 2020) as in other cervids (Klein 1965, Plard et al. 2015). On Vega, there was harvest-induced directional selection for smaller calves (Kvalnes et al. 2016), which was caused by largesized females being more likely to lose their calves during the hunt. Calves constitute a large part of the harvest on Vega, and large females produce more and larger calves. These females also use open areas more frequently, exposing themselves and their calves to a higher risk of being shot (Ofstad et al. 2020). Conversely, late-born calves were more often produced by smaller cows that use open areas less frequently. This introduces age-dependent selection, as young females give birth later than prime-aged females (Kvalnes et al. 2016). Because additive genetic variance was present for both body mass and birth date (Kvalnes et al. 2016), we would also expect selection for earlier calving as a response to earlier green-up in the area (Park et al. 2016). However, because of the harvest-induced selection for later birth, we may rather observe increasing maladaptation to the prevailing environmental conditions in the moose population at Vega.

\subsection{Subtle pathways to harvest selection: the importance of animal behaviour}

Studies of harvest selection have often focussed on direct selection for specific phenotypes such as horn or antler size or body mass (Proaktor et al. 2007, Pigeon et al. 2016). Nonetheless, it has recently become evident that harvest selection may also operate through more subtle pathways, such as selection for specific behavioural strategies (Leclerc et al. 2017 , 2019). In this context, the use of habitat types with varying degrees of cover may be relevant, in particular since hunting for moose and other ungulates often requires open areas with good visibility for the hunters to spot and safely kill the animal. Accordingly, we found that the harvest mortality of yearlings and adult bulls was higher among those that more often used open areas, and the same was true for calves of mothers that frequently used open areas (Ofstad et al. 2020). The result was a clear fitness cost with respect to survival and recruitment for individuals using open habitats. Such habitats, however, are frequently used by moose at Vega (Herfindal et al. 2009, Ofstad et al. 2019) and elsewhere (Nikula et al. 2004, Bjørneraas et al. 2011, Allen et al. 2017), probably because they offer excellent foraging opportunities with abundant forage of high quality (Sviland 2001, but see Allen et al. 2017). In fact, cows that more often used open areas had higher twinning rates and heavier calves than those exhibiting low use of such areas (Sviland 2001, Klaussen 2012, Ofstad et al. 2020). At Vega, these open areas are often agricultural fields for grass production, but elsewhere similar benefits can be gained by using clear-cuts with rejuvenating forest (Wam et al. 2010, 2016, Bjørneraas et al. 2012) or other types of deciduous forests that offer high-quality forage for moose (Allen et al. 2017). The propensity to use humanmade habitats thus induces a fitness benefit with respect to reproduction, but at the cost of reduced survival because of a higher risk of being shot (Ofstad et al. 2020). This results in a weak and nonsignificant cost among both males and females of using open areas, but the net gain or cost of using these areas depends on the harvest pressure (Ofstad et al. 2020).

\subsection{Harvesting effects on inbreeding}

In small and/or isolated populations, such as the Vega moose population, breeding among closely related individuals is common. Inbreeding is typi- 
cally associated with reduced heterozygosity and can have severe fitness consequences (Charlesworth \& Charlesworth 1987, Hedrick \& Kalinowski 2000, Keller \& Waller 2002). The level of inbreeding varies among individuals at Vega and fluctuates over time, partly due to immigration events (Herfindal et al. 2014a). Based on the pedigree of the Vega moose, the inbreeding coefficient $(F)$, was on average 0.12 $(\mathrm{SD}=0.11)$, with an annual value close to 0.20 in some years (Haanes et al. 2013). As a result, the level of genetic variation in the Vega moose population was substantially lower than in the mainland moose population (Haanes et al. 2011, 2013). This level of inbreeding is similar to what is observed in other small and isolated animal populations (Crnokrak \& Roff 1999, Marr et al. 2006, Bozzuto et al. 2019).

A number of strategies to avoid inbreeding exist among animals, such as sex-specific juvenile dispersal or short-term migration during the rut (Blouin \& Blouin 1988). However, as such strategies may not always be possible to adopt, individuals may have to choose between mating with a relative or simply not reproducing. The high relatedness among moose on Vega (Haanes et al. 2013, Herfindal et al. 2014a) and the limited possibilities to disperse suggest that moose on Vega face such a trade-off. The highest recorded inbreeding level in a single year was 0.47 , and several cases of father-daughter breeding were recorded (Haanes et al. 2013, Herfindal et al. 2014a). In these cases, inbreeding avoidance was clearly traded off for the chance to reproduce. When the population structure allowed for it, however, as in years with a high number of males available for mating, more even sex ratios, and high population sizes, there was clear evidence of inbreeding avoidance (Herfindal et al. 2014a). Mating with close relatives was found to have fitness consequences, as offspring from closely related parents were born later and were generally smaller, and inbred adult females had lower twinning rates than outbred females (Haanes et al. 2013). Such fitness consequences of inbreeding may in turn lead to increased individual heterogeneity in reproduction and survival, and reduced mean individual fitness (Bozzuto et al. 2019), with likely effects on population dynamics and genetic drift in the Vega moose population.

\section{CONCLUSIONS AND FUTURE PROSPECTS}

Studies of the moose population on the island of Vega have shown how harvesting can have direct and indirect consequences for individual perfor- mance and population dynamics, and demonstrate the complexity of human impacts on wild populations. These results are based on a combination of theoretical modelling and long-term empirical studies of individual life histories, and provide us with a deeper understanding of how harvesting and other anthropogenic factors shape ecological and evolutionary processes in natural populations. One clear take-home message from these results is that longterm sustainability is reached by more conservative age- and sex-distributions than what is indicated in deterministic models of maximum sustainable yield. Applying traditional harvesting models that do not acknowledge demographic consequences of skewed age- and sex-ratios can lead to restrictions in mechanisms that reduce genetic drift, such as inbreeding avoidance and mate choice (Sæther \& Engen 2019). For harvesting to be sustainable, such processes must be accounted for. Moreover, managers must realise that harvesting is selective on phenotypes and that this selectivity has demographic consequences that affect long-term sustainability.

An important question is how the effects of harvesting interact with ongoing climate change (Gamelon et al. 2019), for instance through age- or sexspecific sensitivities to climate variation (Herfindal et al. 2015, Lee et al. 2021 in this Special). However, because range shifts or changes in large-scale movement patterns such as seasonal migrations are central mechanisms in animals' responses to climate change (Morrison et al. 2021), the study at Vega may be less ideal for generating general results about harvesting under climate change. Similarly, the lack of predation by large carnivores may constrain the generality of the results from the Vega moose population. Still, many ungulate populations worldwide are small and isolated, with few natural predators, and living in highly human-modified landscapes (Chapron et al. 2014, Ripple et al. 2014, Tucker et al. 2018). The results from the Vega moose may be highly relevant for understanding the dynamics in such populations.

The value of long-term, individual-based timeseries in ecological and evolutionary research cannot be overemphasised (Clutton-Brock \& Sheldon 2010, Festa-Bianchet et al. 2019). The importance of individual-based data becomes particularly evident when we observe the role that behaviours such as movement and mate choice play in demographic processes. Indeed, because animal behaviour is greatly affected by any type of human activity (Tucker et al. 2018), understanding human impact on animal populations requires behavioural observations. Studying how behaviour contributes to demo- 
graphic processes often requires a different set of individual-based data, including metrics other than reproduction and survival. There is thus an urgent need to obtain data sets similar to the one available for the moose population at Vega to get more insights into behavioural processes and how they interact with harvesting and other human activities to affect the dynamics and long-term persistence of populations.

Acknowledgements. In addition to financial support from the Research Council of Norway (RCN) to the project Sustain (project no. 244647), research was supported through RCN Centres of Excellence funding scheme (project no. 223257), and the Norwegian Environment Agency. We are particularly grateful to hunters, managers, and the general public on Vega for the permission to conduct our studies on their island.

\section{LITERATURE CITED}

Allen AM, Dorey A, Malmsten J, Edenius L, Ericsson G, Singh NJ (2017) Habitat-performance relationships of a large mammal on a predator-free island dominated by humans. Ecol Evol 7:305-319

Angeloff M, Bjørklund P, Bryn A, Hofsten J, Rekdal Y (2004) Vegetasjon og skog på Vega. NIJOS Rapport 21/04. Norwegian Land and Forest Mapping, Ås

Apollonio M, Andersen R, Putman R (2010) European ungulates and their management in the $21^{\text {st }}$ century. Cambridge University Press, Cambridge

Beddington JR (1974) Age structure, sex ratio and population density in the harvesting of natural animal populations. J Appl Ecol 11:915-924

Bjørneraas K, Solberg EJ, Herfindal I, Sæther BE (2009) Large-scale spatiotemporal variation in calf sex ratio ces): An effect of density-dependent decrease in maternal condition? Can J Zool 87:346-355

* Bjørneraas K, Solberg EJ, Herfindal I, Rolandsen CM and others (2011) Moose habitat use at multiple temporal scales in a human-altered landscape. Wildl Biol 17:44-54

Bjørneraas K, Herfindal I, Solberg EJ, Sæther BE, van Moorter B, Rolandsen CM (2012) Habitat quality influences population distribution, individual space use and functional response in habitat selection by a large herbivore. Oecologia 168:231-243

Bleu J, Gamelon M, Sæther BE (2016) Reproductive costs in terrestrial male vertebrates: insights from bird studies. Proc R Soc B 283:20152600

Blouin SF, Blouin M (1988) Inbreeding avoidance behaviors. Trends Ecol Evol 3:230-233

$\mathrm{B} ø \mathrm{~S}$, Hjeljord O (1991) Do continental moose ranges improve during cloudy summers? Can $J$ Zool 69: 1875-1879

Bozzuto C, Biebach I, Muff S, Ives AR, Keller LF (2019) Inbreeding reduces long-term growth of alpine ibex populations. Nat Ecol Evol 3:1359-1364

Cam E, Aubry LM, Authier M (2016) The conundrum of heterogeneities in life history studies. Trends Ecol Evol 31: 872-886

Caughley G (1977) Analysis of vertebrate populations. Blackburn Press, Caldwell, NJ
Chapron G, Kaczensky P, Linnell JDC, von Arx M and others (2014) Recovery of large carnivores in Europe's modern human-dominated landscapes. Science 346: 1517-1519

* Charlesworth D, Charlesworth B (1987) Inbreeding depression and its evolutionary consequences. Annu Rev Ecol Syst 18:237-268

Clutton-Brock TH (ed) (1988) Reproductive success: studies of individual variation in contrasting breeding systems. University of Chicago Press, Chicago, IL

Clutton-Brock T, Sheldon BC (2010) Individuals and populations: the role of long-term, individual-based studies of animals in ecology and evolutionary biology. Trends Ecol Evol 25:562-573

Clutton-Brock TH, Guinness FE, Albon SD (1982) Red deer: behavior and ecology of two sexes. Wildlife Behavior and Ecology Series. University of Chicago Press, Chicago, IL

Coltman DW (2008) Evolutionary rebound from selective harvesting. Trends Ecol Evol 23:117-118

* Coulson T, Schindler S, Traill L, Kendall BE (2018) Predicting the evolutionary consequences of trophy hunting on a quantitative trait. J Wildl Manag 82:46-56

Crnokrak P, Roff DA (1999) Inbreeding depression in the wild. Heredity 83:260-270

* Edeline E, Carlson SM, Stige LC, Winfield IJ and others (2007) Trait changes in a harvested population are driven by a dynamic tug-of-war between natural and harvest selection. Proc Natl Acad Sci USA 104:15799-15804

Engen S, Lande R, Sæther BE (1997) Harvesting strategies for fluctuating populations based on uncertain population estimates. J Theor Biol 186:201-212

Engen S, Bakke Ø, Islam A (1998) Demographic and environmental stochasticity-concepts and definitions. Biometrics 54:840-846

*Engen S, Lande R, Sæther BE (2003) Demographic stochasticity and Allee effects in populations with two sexes. Ecology 84:2378-2386

Engen S, Lande R, Sæther BE (2005a) Effective size of a fluctuating age-structured population. Genetics 170: 941-954

* Engen S, Lande R, Sæther BE, Weimerskirch H (2005b) Extinction in relation to demographic and environmental stochasticity in age-structured models. Math Biosci 195: 210-227

Engen S, Lande R, Sæether BE, Festa-Bianchet M (2007a) Using reproductive value to estimate key parameters in density-independent age-structured populations. J Theor Biol 244:308-317

Engen S, Ringsby TH, Sæther BE, Lande R, Jensen H, Lillegård M, Ellegren H (2007b) Effective size of fluctuating populations with two sexes and overlapping generations. Evolution 61:1873-1885

*Engen S, Lande R, Sæether BE, Dobson FS (2009) Reproductive value and the stochastic demography of agestructured populations. Am Nat 174:795-804

*Ericsson G, Wallin K, Ball JP, Broberg M (2001) Age-related reproductive effort and senescence in free-ranging moose, Alces alces. Ecology 82:1613-1620

Festa-Bianchet M, Mysterud A (2018) Hunting and evolution: theory, evidence, and unknowns. J Mammal 99: 1281-1292

Festa-Bianchet M, Côté SD, Hamel S, Pelletier F (2019) Long-term studies of bighorn sheep and mountain goats reveal fitness costs of reproduction. J Anim Ecol 88: 1118-1133 
Gaillard JM, Yoccoz NG (2003) Temporal variation in survival of mammals: a case of environmental canalization? Ecology 84:3294-3306

Gaillard JM, Festa-Bianchet M, Yoccoz NG, Loison A, Toïgo C (2000) Temporal variation in fitness components and population dynamics of large herbivores. Annu Rev Ecol Syst 31:367-393

* Gamelon M, Sandercock BK, Sæther BE (2019) Does harvesting amplify environmentally induced population fluctuations over time in marine and terrestrial species? J Appl Ecol 56:2186-2194

Grafen A (2006) A theory of Fisher's reproductive value. J Math Biol 53:15-60

*Haanes H, Røed KH, Solberg EJ, Herfindal I, Sæther BE (2011) Genetic discontinuities in a continuously distributed and highly mobile ungulate, the Norwegian moose. Conserv Genet 12:1131-1143

Haanes H, Markussen SS, Herfindal I, Røed KH and others (2013) Effects of inbreeding on fitness-related traits in a small isolated moose population. Ecol Evol 3:4230-4242

Hamel S, Gaillard JM, Yoccoz NG, Loison A, Bonenfant C, Descamps S (2010) Fitness costs of reproduction depend on life speed: empirical evidence from mammalian populations. Ecol Lett 13:915-935

*Hamel S, Gaillard JM, Yoccoz NG, Bassar RD and others (2018) General conclusion to the special issue Moving forward on individual heterogeneity. Oikos 127:750-756

Hedrick PW, Kalinowski ST (2000) Inbreeding depression in conservation biology. Annu Rev Ecol Syst 31:139-162

Herfindal I, Solberg EJ, Sæther BE, Høgda KA, Andersen R (2006a) Environmental phenology and geographical gradients in moose body mass. Oecologia 150:213-224

*Herfindal I, Sæther BE, Solberg EJ, Andersen R, Høgda KA (2006b) Population characteristics predict responses in moose body mass to temporal variation in the environment. J Anim Ecol 75:1110-1118

KHerfindal I, Tremblay JP, Hansen BB, Solberg EJ, Heim M, Sæther BE (2009) Scale dependency and functional response in moose habitat selection. Ecography 32:849-859

* Herfindal I, Haanes H, Røed KH, Solberg EJ, Markussen SS, Heim M, Sæther BE (2014a) Population properties affect inbreeding avoidance in moose. Biol Lett 10:20140786

Herfindal I, Haanes H, Solberg EJ, Røed KH, Høgda KA, Sæther BE (2014b) Moose body mass variation revisited: disentangling effects of environmental conditions and genetics. Oecologia 174:447-458

* Herfindal I, van de Pol M, Nielsen JT, Sæther BE, Møller AP (2015) Climatic conditions cause complex patterns of covariation between demographic traits in a long-lived raptor. J Anim Ecol 84:702-711

Keller LF, Waller DM (2002) Inbreeding effects in wild populations. Trends Ecol Evol 17:230-241

Klaussen AJ (2012) Fitness consequences of selection of home range in moose (Alces alces). MSc thesis, Norwegian University of Science and Technology (NTNU), Trondheim

Klein DR (1965) Ecology of deer range in Alaska. Ecol Monogr 35:259-284

Kvalnes T, Sæther BE, Haanes H, Røed KH, Engen S, Solberg EJ (2016) Harvest-induced phenotypic selection in an island population of moose, Alces alces. Evolution 70 : $1486-1500$

Lande R (1998) Anthropogenic, ecological and genetic factors in extinction and conservation. Res Popul Ecol (Kyoto) 40:259-269

Lande R, Engen S, Sæther BE (1995) Optimal harvesting of fluctuating populations with a risk of extinction. Am Nat 145:728-745

Kande R, Sæther BE, Engen S (1997) Threshold harvesting for sustainability of fluctuating resources. Ecology 78: $1341-1350$

Lande R, Engen S, Sæther BE (2003) Stochastic population dynamics in ecology and conservation. Oxford Series in Ecology and Evolution. Oxford University Press, New York, NY

Lavsund S, Nygrén T, Solberg EJ (2003) Status of moose populations and challenges to moose management in Fennoscandia. Alces 39:109-130

Keclerc M, Zedrosser A, Pelletier F (2017) Harvesting as a potential selective pressure on behavioural traits. J Appl Ecol 54:1941-1945

* Leclerc M, Zedrosser A, Swenson JE, Pelletier F (2019) Hunters select for behavioral traits in a large carnivore. Sci Rep 9:12371

Lee AM, Engen S, Sæther BE (2011) The influence of persistent individual differences and age at maturity on effective population size. Proc R Soc B 278:3303-3312

ㄴLee AM, Sæther BE, Markussen SS, Engen S (2017) Modelling time to population extinction when individual reproduction is autocorrelated. Ecol Lett 20:1385-1394

* Lee AM, Myhre AM, Markussen SS, Engen S and others (2020) Decomposing demographic contributions to the effective population size in an age-structured harvested moose population. Mol Ecol 29:56-70

* Lee AM, Jarillo J, Peeters B, Hansen BB, Cao-García FJ, Sæther BE, Engen S (2021) Population responses to harvesting in fluctuating environments. Clim Res (in press), doi:10.3354/cr01656

*Markussen SS, Loison A, Herfindal I, Solberg EJ and others (2018) Fitness correlates of age at primiparity in a hunted moose population. Oecologia 186:447-458

Markussen SS, Herfindal I, Loison A, Solberg EJ and others (2019) Determinants of age at first reproduction and lifetime breeding success revealed by full paternity assignment in a male ungulate. Oikos 128:328-337

*Marr AB, Arcese P, Hochachka WM, Reid JM, Keller LF (2006) Interactive effects of environmental stress and inbreeding on reproductive traits in a wild bird population. J Anim Ecol 75:1406-1415

McLoughlin PD, Gaillard JM, Boyce MS, Bonenfant C and others (2007) Lifetime reproductive success and composition of the home range in a large herbivore. Ecology 88: 3192-3201

Morrison TA, Merkle JA, Hopcraft JGC, Aikens EO and others (2021) Drivers of site fidelity in ungulates. J Anim Ecol 90:955-966

KMorrongiello JR, Sweetman PC, Thresher RE (2019) Fishing constrains phenotypic responses of marine fish to climate variability. J Anim Ecol 88:1645-1656

* Mysterud A, Coulson T, Stenseth NC (2002) The role of males in the dynamics of ungulate populations. J Anim Ecol 71:907-915

* Neumann W, Singh NJ, Stenbacka F, Malmsten J, Wallin K, Ball JP, Ericsson G (2020) Divergence in parturition timing and vegetation onset in a large herbivore-differences along a latitudinal gradient. Biol Lett 16:20200044

Nikula A, Heikkinen S, Helle E (2004) Habitat selection of adult moose Alces alces at two spatial scales in central Finland. Wildl Biol 10:121-135

Ofstad EG (2019) Causes and consequences of variation in resource use and social structure in ungulates. $\mathrm{PhD}$ the- 
sis, Norwegian University of Science and Technology (NTNU), Trondheim

Ofstad EG, Herfindal I, Solberg EJ, Heim M, Rolandsen CM, Sæther BE (2019) Use, selection, and home range properties. Complex patterns of individual habitat utilization. Ecosphere 10:e02695

Ofstad EG, Markussen SS, Sæther BE, Solberg EJ and others (2020) Opposing fitness consequences of habitat use in a harvested moose population. J Anim Ecol 89:1701-1710

Park T, Ganguly S, Tømmervik H, Euskirchen ES and others (2016) Changes in growing season duration and productivity of northern vegetation inferred from long-term remote sensing data. Environ Res Lett 11:084001

* Pigeon G, Festa-Bianchet M, Coltman DW, Pelletier F (2016) Intense selective hunting leads to artificial evolution in horn size. Evol Appl 9:521-530

* Plard F, Gaillard JM, Coulson T, Hewison AJM and others (2015) The influence of birth date via body mass on individual fitness in a long-lived mammal. Ecology 96: 1516-1528

Proaktor G, Coulson T, Milner-Gulland EJ (2007) Evolutionary responses to harvesting in ungulates. J Anim Ecol 76: 669-678

Ripple WJ, Estes JA, Beschta RL, Wilmers CC and others (2014) Status and ecological effects of the world's largest carnivores. Science 343:1241484

* Rolandsen CM, Solberg EJ, Sæther BE, van Moorter B, Herfindal I, Bjørneraas K (2017) On fitness and partial migration in a large herbivore-migrant females have higher reproductive performance than resident females. Oikos 126:547-555

S wegian moose in relation to climate along a latitudinal gradient. J Wildl Manag 49:977-983

Sæther BE, Engen S (2019) Towards a predictive conservation biology: the devil is in the behaviour. Philos Trans R Soc B 374:20190013

Sæather BE, Haagenrud H (1983) Life history of the moose (Alces alces): fecundity rates in relation to age and carcass weight. J Mammal 64:226-232

Sæther BE, Haagenrud H (1985) Life history of the moose Alces alces: relationship between growth and reproduction. Holarct Ecol 8:100-106

Sæther BE, Heim M (1993) Ecological correlates of individual variation in age at maturity in female moose (Alces alces): the effects of environmental variability. J Anim Ecol 62:482-489

Sæther BE, Andersen R, Hjeljord O, Heim M (1996) Ecological correlates of regional variation in life history of the moose Alces alces. Ecology 77:1493-1500

Sather BE, Engen S, Solberg EJ (2001) Optimal harvest of age-structured populations of moose Alces alces in a fluctuating environment. Wildl Biol 7:171-179

Sæether BE, Solberg EJ, Heim M (2003) Effects of altering sex ratio structure on the demography of an isolated moose population. J Wildl Manag 67:455-466

Sæather BE, Solberg EJ, Heim M, Stacy JE, Jakobsen KS, Olstad R (2004) Offspring sex ratio in moose Alces alces in relation to paternal age: an experiment. Wildl Biol 10: 51-57

Sæther BE, Engen S, Solberg EJ, Heim M (2007) Estimating the growth of a newly established moose population using reproductive value. Ecography 30:417-421
Sæther BE, Engen S, Solberg EJ (2009) Effective size of harvested ungulate populations. Anim Conserv 12:488-495

Sand H (1996) Life history patterns in female moose (Alces alces): the relationship between age, body size, fecundity and environmental conditions. Oecologia 106:212-220

Solberg EJ, Rolandsen CM, Heim M, Grøtan V and others (2006) Moose in Norway. An analysis of material collected by moose hunters 1966-2004. NINA Report 125. Norwegian Institute for Nature Research, Trondheim

Solberg EJ, Heim M, Grøtan V, Sæether BE, Garel M (2007) Annual variation in maternal age and calving date generate cohort effects in moose (Alces alces) body mass. Oecologia 154:259-271

Solberg EJ, Garel M, Heim M, Grøtan V, Sæther BE (2008) Lack of compensatory body growth in a high performance moose Alces alces population. Oecologia 158: 485-498

Solberg EJ, Rolandsen CM, Heim M, Linnell JDC, Herfindal I, Sæther BE (2010) Age and sex-specific variation in detectability of moose (Alces alces) during the hunting season: implications for population monitoring. Eur J Wildl Res 56:871-881

Solberg EJ, Heim M, Rolandsen CM, Sæther BE, Arnemo JM (2011) Immobilization and radiocollaring of moose at Vega, 1992-2010. Consequences for animal welfare, body condition, reproduction and survival. NINA Report 658. Norwegian Institute for Nature Research, Trondheim

Stearns SC (1992) The evolution of life histories. Oxford University Press, Oxford

* Stubsjøen T, Sæther BE, Solberg EJ, Heim M, Rolandsen CM (2000) Moose (Alces alces) survival in three populations in northern Norway. Can J Zool 78:1822-1830

Sviland M (2001) Individuelle variasjoner i vekt i forhold til leveområde-egenskaper i en isolert elgbestand. MScthesis, Norwegian University of Science and Technology (NTNU), Trondheim

* Tucker MA, Böhning-Gaese K, Fagan WF, Fryxell JM and others (2018) Moving in the Anthropocene: global reductions in terrestrial mammalian movements. Science 359: 466-469

UN General Assembly (2015) Transforming our world: the 2030 Agenda for Sustainable Development: A/RES/70/1. Seventieth Session of the UN General Assembly, New York, NY

*van Noordwijk AJ, de Jong G (1986) Acquisition and allocation of resources: their influence on variation in life history tactics. Am Nat 128:137-142

Veiberg V, Rolandsen CM, Heim M, Solberg EJ (2016) Extent of orphaned calves after moose and red deer hunting. NINA Report 1197. Norwegian Institute for Nature Research, Trondheim

* Vindenes Y, Engen S, Sæther BE (2008) Individual heterogeneity in vital parameters and demographic stochasticity. Am Nat 171:455-467

*Wam HK, Hjeljord O, Solberg EJ (2010) Differential forage use makes carrying capacity equivocal on ranges of Scandinavian moose (Alces alces). Can J Zool 88: 1179-1191

* Wam HK, Histøl T, Nybakken L, Solberg EJ, Hjeljord O (2016) Transient nutritional peak in browse foliage after forest clearing advocates cohort management of ungulates. Basic Appl Ecol 17:252-261 